\title{
AN UNUSUAL SHORT NON-TORTUOUS STRAIGHT SPLENIC ARTERY IN MIDDLE EAST POPULATION: A CASE REPORT
}

\author{
Shweta Chaudhary1, Rishi Kumar Bharti2, Hemali Deshpande 3 \\ ${ }_{1}^{1}$ Assistant Professor, Department of Anatomy, College of Medicine, King Khalid University, Kingdom of Saudi Arabia. \\ ${ }^{2}$ Assistant Professor, Department of Community Medicine, College of Medicine, King Khalid University, Kingdom of Saudi Arabia. \\ ${ }^{3}$ Assistant Professor, Department of Anatomy, College of Medicine, King Khalid University, Kingdom of Saudi Arabia.
}

\begin{abstract}
The present case describes a rare finding of a non-tortuous splenic artery arising from coeliac trunk. The artery originated along with left gastric and common hepatic artery. Artery was $6.5 \mathrm{~cm}$ in length and showed lack of tortuosity what is considered as unique feature of present case and had a remarkable straight course. The artery divided into two branches before entering into hilum and enclosed splenic vein. Artery divided into six terminal branches as it entered spleen. The knowledge of these variations are of significant importance during surgical and radiological procedure of upper abdominal region to avoid any catastrophic complications.
\end{abstract}

\section{KEYWORDS}

Non-Tortuous, Splenic Artery Abdomen, Spleen.

HOW TO CITE THIS ARTICLE: Chaudhary S, Bharti RK, Deshpande H. An unusual short non-tortuous straight splenic artery in middle east population: a case report. J. Evolution Med. Dent. Sci. 2016;5(57):3968-3969, DOI: 10.14260/jemds/2016/907

\section{INTRODUCTION}

The origin of vascular trunks can be correlated embryologically. The coeliac trunk, the first major branch of the abdominal aorta originates at the level of the T12-L1 intervertebral disk. Its average length is approximately $1-2 \mathrm{~cm}$ before trifurcation. The classic branching pattern in which the left gastric artery originates as the first branch and the coeliac trunk divides into common hepatic and splenic arteries. The splenic artery is usually the largest (6-10 $\mathrm{mm}$ in diameter) and most tortuous branch of the coeliac artery having an average length of $13 \mathrm{~cm}$ (Range, 8-32 cm). The straight distance from the origin of the splenic artery from the coeliac trunk to the point of commencement of the hilar branches was measured as was the total length of the artery between these two points. The ratio of these two measurements is called the "index of tortuosity." The tortuous route of the vessel is accentuated by the direction of its major branches, which is roughly perpendicular to the main trajectory. The spleen's blood storage capacity may contribute to the characteristic agedependent alterations of the shape and course of the splenic artery.

\section{CASE REPORT}

The purpose of present commentary is to report an unusual non-tortuous and straight splenic artery, which was encountered during routine cadaveric dissection of $35 \mathrm{yrs}$. old cadaver by faculty of Department of Anatomy. The rare finding showed remarkably short course due to lack of tortuosity and had relatively straight course as it arose from coeliac trunk to its termination till it entered spleen. Artery was $6.5 \mathrm{~cm}$ in length and $0.5 \mathrm{~cm}$ in diameter and passed in relation with superior border of pancreas. The artery divided into two branches before it entered in the hilum of spleen.

Financial or Other, Competing Interest: None.

Submission 10-06-2016, Peer Review 05-07-2016,

Acceptance 11-07-2016, Published 18-07-2016.

Corresponding Author:

Dr. Shweta Chaudhary,

Abha, Saudi Arabia, King Khalid University.

E-mail: drshwetarishi@gmail.com

DOI: $10.14260 /$ jemds/2016/907
First branch divided into three and second into two terminal branches as it entered spleen. Divisions of splenic artery enclosed splenic vein before entering into hilum. Spleen weighed $180 \mathrm{mg}$. Stomach was normal in size and shape. Left gastric artery was normal. Common hepatic artery was normal.

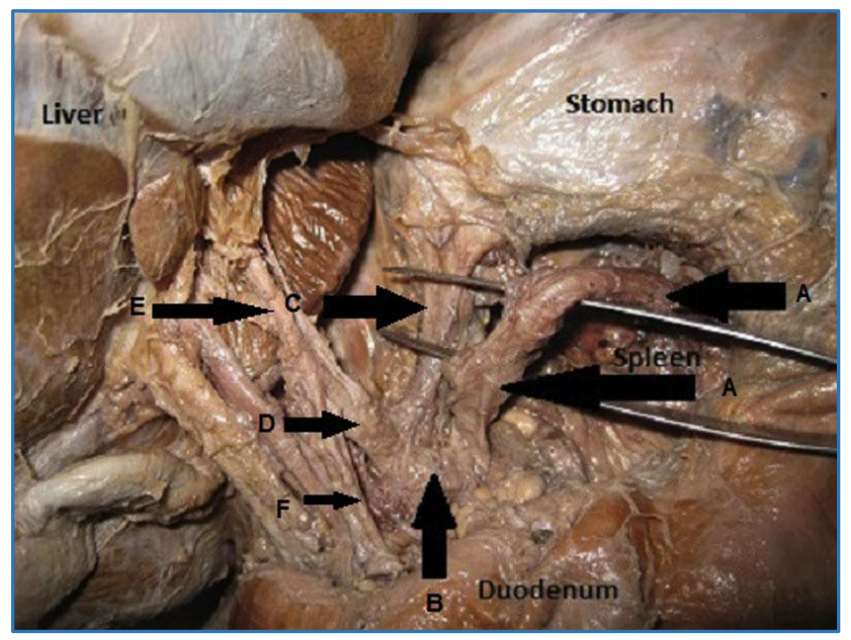

Fig. 1: Showing A-Short and Straight Non tortuous Splenic artery, B-Coeliac Trunk, C-Left Gastric Artery, D-Common Hepatic Artery, E-Hepatic Artery, F-Gastro duodenal Artery

\section{DISCUSSION}

The tortuous course of the splenic artery is considered so variable that no two arteries are alike, but the tortuosity of the artery is absent in infants and children. Tortuosity was seen in only $10 \%$ of adults; thus, the characteristic tortuosity of the splenic artery appears to develop with age. ${ }^{(1)}$

Splenic arteries are end arteries in the strictest sense and interference with the blood supply to the spleen will result in necrotic areas in the organ.(2)

The artery originated from the coeliac trunk in $90.6 \%$ followed by abdominal aorta $8.1 \%$ and other sites $0.3 \%$. A suprapancreatic course of the artery was commonly observed in $74.1 \%$ followed by enteropancreatic in $18.5 \%$, 
intrapancreatic in $4.6 \%$, and retropancreatic in $2.8 \%$ courses. The splenic artery divided into terminal branches in $97 \%$. In $2.8 \%$, it passed through the hilum of spleen without dividing. Two terminal branches were the most common (63.1\%) followed by four (18.8\%), six (9.7\%), and more than six (5.6\%) branches.(3)

Tortuosity of the splenic artery and calcification of the vessel wall are typical additional findings on plain abdominal $\mathrm{x}$-ray. The combination of both anomalies is common in elderly persons presenting without symptoms of splenic ischaemia. Its pathogenesis is thought to be multifactorial. In infancy and childhood, the splenic artery is stretched in its entire course. A growing difference between the length of the vessel and the distance between its origin and the splenic hilum gives rise to tortuosity. The artery's proximal segment is involved more frequently and more severely than the distal one. Neither tortuosity nor calcification should be taken to be risk factors for the comparatively common splenic artery aneurysm.(4)

Variations in its tortuosity in man and possible relationships with age, sex by measuring "index of tortuosity" suggested increasing tortuosity with age; although, in one 10year-old girl, marked tortuosity was demonstrated on angiography. At present, there is apparently no satisfactory explanation for tortuosity of the splenic artery.(5) Our case is contrary to their observation as here artery lacks usual feature of tortuosity and was remarkably short and worth considered to be reported.

In the pig and dog, the artery was nearly straight throughout its length with a very low index of tortuosity. The artery was significantly more tortuous in the rhesus macaque and baboon than in both pig and dog with a single large convolution present in the proximal one-third. In humans, the artery is commonly tortuous throughout its length and is significantly more tortuous than in the pig and $\operatorname{dog}(\mathrm{P}<0.001)$, but not significantly more tortuous than in the baboon $(\mathrm{P}>0.1)$ and only just significantly more so than in the rhesus macaque $(\mathrm{P}<0.05)$. The speculation that the tortuosity of the artery maybe related to habitual posture is not supported by results in the wholly orthograde humans.(6)

We present a unique case of non-tortuous straight artery in an adult. Such finding has not been reported in the past. Non-tortuosity leads to the artery unable to compensate for increased demand of blood supply to spleen during expansion of stomach. Therefore, may lead to aneurysms, atheroma, and sclerosis in intimal and medial layer of splenic artery.(7) Straight arteries could be significant in calcification of arteries. Such variations could be significant to surgeons operating in lesser sac during drainage of pseudo pancreatic cyst. ${ }^{\left({ }^{8}\right)}$ Shorter course makes artery vulnerable to injury. Radiologists and surgeons should be aware of such variations.

\section{CONCLUSION}

Preoperative awareness of such variations on the part of the surgical team is extremely important to avoid iatrogenic arterial injury particularly in light of the increasing number of laparoscopic interventions. The number of angiographic studies performed are gradually increasing; therefore, knowledge of normal and variant anatomic features has become more important than in the past. At present, there is apparently no satisfactory explanation for tortuosity of the splenic artery. Every practicing radiologist and surgeon must have in-depth knowledge of this topic for better knowledge of clinical conditions associated with artery.

\section{REFERENCES}

1. Sahni DA, Indar Jit B, Gupta CN, et al. Branches of the splenic artery and splenic arterial segments. Clin Anat 2003;16(5):371-7.

2. Carmel AG. The tortuous splenic artery. Anat Rec 1925;29:352.

3. Pandey SK, Bhattacharya S, Mishra RN, et al. Anatomical variations of the splenic artery and its clinical implications. Clin Anat 2004;17(6):497-502.

4. Golder WA. Tortuosity and calcification of the splenic artery-more than an additional finding. Der Radiologe 2008;48(11):1066-74.

5. Sylvester PA, Stewart R, Ellis H. Tortuosity of the human splenic artery. Clin Anat 1995;8(3):214-8.

6. Borley NR, McFarlane JM, Ellis H. A comparative study of the tortuosity of the splenic artery. Clin Anat 1995;8(3):219-21.

7. Hazirolan T, Metin Y, Karaosmanoglu AD, et al. Mesenteric arterial variations detected at MDCT angiography of abdominal aorta. AJR 2009;192(4):1097-102.

8. Majeski J. Splenic artery tortuosity simulating a splenic artery aneurysm. South Med J 1998;91(10):949-51. 